\title{
Genetic Variability of Fruit Set, Fruit Weight, and Yield in a Tomato Population Grown in Two High-temperature Environments
}

\author{
Linda Wessel-Beaver ${ }^{1}$ \\ Agricultural Experiment Station, University of Puerto Rico, Mayaguez, PR 00681
}

J.W. Scott ${ }^{2}$

Gulf Coast Research and Education Center, University of Florida, 5007 60th Street East, Bradenton, FL 34203

\begin{abstract}
Additional index words. Lycopersicon esculentum, heritability, genetic variance, genetic correlation, genotype $\times$ environment interaction

Abstract. Heritabilities $\left(\mathrm{h}^{2}\right)$ and genetic correlations between percent fruit set, yield, and fruit weight were estimated from one summer planting each in Florida and Puerto Rico of $100 \mathrm{~S}$, tomato (Lycopersicon esculentum Mill.) families from a synthetic population. Single-location $h^{2}$ was high for all traits. Across-locations $h^{2}$ was low for yield, intermediate for fruit set, and high for fruit weight. Genotype $x$ environment interaction $(G \times E)$ was 1$)$ the only significant component of variance for yield, 2) somewhat important for fruit set, and 3) not an important variance component for fruit weight. The greater importance of genetic variance compared to $G \times E$ variance explains why across-location heritabilities for fruit weight and fruit set were high. Genetic correlations between fruit set and weight were strongly negative, while those between yield and set were large and positive. Yields under high temperatures may increase with selection for fruit set, but a reduction in fruit weight would be expected in this population and those with similar genetic correlations.
\end{abstract}

Improved tomato fruit set under high temperatures would help to extend the production season in areas of the tropics and subtropics such as southern Florida and the Caribbean. For successful summer production of tomatoes, yield and fruit size (measured as weight) must also be considered. Cuartero and Cubero (1982) reported nonsignificant genetic correlations between yield and fruit weight under normal temperatures. While several breeders working with high-temperature fruit-setting ability have found negative phenotypic correlations between fruit set and fruit weight (Scott et al., 1986; Villareal and Lai, 1978), estimates of genetic correlations between these traits have not previously been reported. Phenotypic correlations are not always of the same magnitude, nor even the same sign, as genetic correlations.

Estimates of variance components and heritabilities have been determined in tomato for fruit weight, fruit size, and fruit set in studies using diallel analysis (Cuartero and Cubero, 1982; El Ahmadi and Stevens, 1979; Giberal et al., 1982; Hanna and Hernandez, 1982a) or generation mean analysis (Peirce and Currence, 1959; Shelby et al., 1978; Villareal and Lai, 1978). Of these; only El Ahmadi and Stevens (1979), Shelby et al. (1978), and Villareal and Lai (1978) studied fruit set under high temperatures. Diallel analysis is often not the most appropriate method of estimating genetic variance and $h^{2}$. Hallauer and $\mathrm{Mi}-$ randa (1988) point out that diallel analysis is appropriate for estimating genetic variances only when many randomly chosen

\footnotetext{
Received for publication 20 Mar. 1991. Accepted for publication 27 Apr. 1992 Florida Agricultural Experiment Station Journal Series no. R-02374. This research was supported in part by the U.S. Dept. of Agriculture under CSRS Special Grants 84-CRSR-2-2468 and 84-CRSR-2-2508 managed by the Caribbean Basin Advisory Group (CBAG). The cost of publishing this paper was defrayed in part by the payment of page charges. Under postal regulations, this paper therefore must be hereby marked advertisement solely to indicate this fact.

'Professor.

'Associate Professor.
}

parents are used in the design. A few selected parents were used in the diallel studies mentioned above.

Synthetic populations, both as base populations for variance and covariance estimates and for selection, have been widely used in cross-pollinated but not self-pollinated crops. Examples of self-pollinated crops in which synthetic populations have been used are tobacco (Nicotiana tubacum L.) (Legg et al., 1965) and sorghum [Sorghum bicolor (L.) Moench] (Jan-or-n et al., 1976). Populations can be synthesized in tomato, since crosses are easy to make and large amounts of seed are produced from each cross. The use of $\mathrm{S}_{1}$ families derived from a synthetic population lends itself to studies of genetic variance in tomato since natural self-pollination occurs.

The purpose of this research was to estimate variance components, heritabilities, and correlations between percent fruit set, yield per plant, and fruit weight in a synthetic tomato population under high-temperature conditions to suggest selection strategies for these traits.

\section{$M$ aterials and $M$ ethods}

Field methods. Twenty-eight genotypes were evaluated for heat tolerance and fruit size in Summer 1984 at Isabela and Juana Diaz, P.R., and Bradenton, Fla. From these evaluations, the following seven genotypes were selected for intermating to form a synthetic population: 1) $\mathrm{C} 111 \mathrm{~d}$ : small-fruited, heattolerant line from the Asian Vegetable Research and Development Center, Taiwan; 2) Hawaii 7998: small-fruited, moderately heat-tolerant, indeterminate, bacterial wilt- and bacterial spot-resistant line from Hawaii; 3) 'Freshmarket 9': mediumto large-fruited, heat-tolerant breeding line release from Texas A\&M Univ.; 4) [(Subartic Delight x Fla. MH1) $\times \mathrm{C} 111 \mathrm{~d}] \mathrm{F}_{6}$ : small-fruited, heat-tolerant, jointless breeding line from Florida; 5) $\{$ Fla. $1 \mathrm{~B} \times[($ Walter $\times$ Fla. $\mathrm{MH} 1) \times \mathrm{C} 111 \mathrm{~d}]\} \mathrm{F}_{3}$ : medium-

Abbreviations: $\mathrm{G} \times \mathrm{E}$, genotype $\times$ environment; $h^{2}$, heritability. 
fruited, heat-tolerant breeding line from Florida; 6) 'FloraDade': medium-large-fruited, heat-sensitive but widely adapted, jointless cultivar; and 7) 'Suncoast': heat-sensitive, very largefruited cultivar from Florida. All possible crosses and reciprocals were made in Jan. 1985 (approximating random mating). $F_{1}$ plants of crosses and reciprocals were selfed in Summer 1985. A bulk of 15 seeds of each self was used to plant the $F_{2}$ $\left(\mathrm{S}_{0}\right)$ population in the field. Seed from 100 randomly selected $S_{\text {o }}$ plants were used to plant the replicated $S_{1}\left(F_{3}\right)$ family trials. The $100 \mathrm{~S}_{1}$ families were field-set in Summer 1986 in Juana Diaz, P.R., and Bradenton, Fla., in a reps-in-sets design. At each location, 20 families were randomly assigned to each of five sets (sets contained the same 20 families at each location). Within a set, families were arranged in a randomized completeblock design with three replications. In Florida, sets of $S_{1}$ families were field-set weekly from 30 June to 29 July. Harvesting was done weekly over 3 weeks for each set. The mean high for the 79-day fruiting period was $32.8 \mathrm{C}$ with a range from 28.3 to $35.6 \mathrm{C}$. The mean low during this period was $22.7 \mathrm{C}$ with a range from 20.0 to $25.6 \mathrm{C}$. In Puerto Rico, all groups were field-set 10 June, and two harvests were made over 13 days. The mean high for the fruiting period was $32.2 \mathrm{C}$ with a range from 30.6 to $35.0 \mathrm{C}$. The mean low during this period was $22.0 \mathrm{C}$ with a range of 19.4 to $25.0 \mathrm{C}$. Yield was measured as the average commercial yield per plant in a single row of 11 plants (end plants excluded) spaced 0.5 and $0.6 \mathrm{~m}$ apart in Puerto Rico and Florida, respectively. White on black plastic mulch and staking were used in Florida but not Puerto Rico. Average fruit weight was determined at the first harvest in Puerto Rico and averaged over all harvests in Florida. Percentage of fruit set was determined after harvest on five (in Puerto Rico) or six (in Florida) random plants cut from each plot. The number of enlarged pedicels (an indication that it held a fruit) and thin pedicels (no fruit set) was counted on the first six to eight clusters. Fruit set was calculated as the proportion of enlarged pedicels to total number of pedicels.

Statistical and genetic analyses. Families were divided into sets to minimize experimental error. Family and location effects were considered to be random. Analysis of variance was conducted on each set, and sums of squares and degrees of freedom were pooled over sets. Environmental variance, $\mathrm{G} \times \mathrm{E}$ variance, and genetic variance of $\mathrm{S}_{1}$ family means were estimated by $\sigma^{2} / \mathrm{re}, \sigma_{\mathrm{gxe}}^{2} / \mathrm{e}$, and $\sigma_{\mathrm{g}}^{2}$, respectively (Table 1 ). Broad-sense $\mathrm{h}^{2}$ on an $\mathrm{S}$ family mean basis was estimated as (genetic variance $) /($ genetic variance $+\mathrm{G} \times \mathrm{E}$ variance + environmental variance). Single-location estimates were calculated by eliminating location effects and interactions from the model. Genetic variance among $S_{1}$ family means (equivalent to $F_{3}$ family means) estimates all the additive variance plus a variance component

Table 1. Sources of variation, degrees of freedom, mean squares, and expected mean squares used to estimate variance components and heritabilities.

\begin{tabular}{|c|c|c|c|}
\hline $\begin{array}{l}\text { Source of } \\
\text { variation }\end{array}$ & $\mathrm{df}$ & $\begin{array}{c}\text { Mean } \\
\text { squares }\end{array}$ & $\begin{array}{c}\text { Expected } \\
\text { mean squares }\end{array}$ \\
\hline Environments (E) & 1 & & \\
\hline Sets $(S) / E$ & 8 & & \\
\hline Blocks/S/E & 20 & & \\
\hline$S_{1}$ families $(G) / S$ & 95 & MS3 & $\begin{array}{c}\sigma^{2}+r \sigma_{\mathrm{g} \times e}^{2} \\
+r e \sigma_{\mathrm{g}}^{2}\end{array}$ \\
\hline$G \times E$ & 95 & MS2 & $\sigma^{2}+r \sigma_{\mathrm{g} \times \mathrm{e}}^{2}$ \\
\hline Error & 380 & MS1 & $\sigma^{2}$ \\
\hline
\end{tabular}

${ }^{2} \mathrm{r}=$ three replications and $\mathrm{e}=$ two environments. due to dominance effects (Hallauer and Miranda, 1988). Genetic and phenotypic correlation coefficients were calculated from analysis of covariance analogously to that used to calculate the variance components from analysis of variance. Approximate standard errors of $\mathrm{h}^{2}$ estimates (Hallauer and Miranda, 1988) and correlation coefficients (Falconer, 1981) were determined. Rank correlation coefficients between Florida and Puerto Rico were calculated by assigning ranks 1 to 20 to means of $S_{1}$ families within each of the five sets of families. As above, sums of squares and cross products were pooled across sets.

\section{Results and Discussion}

Plantings in both locations were subjected to similar temperatures, although day and night temperatures were slightly higher in Florida. The sites differed in terms of soil type, cultural practices, rainfall amount, and distribution. Location means differed for all three traits measured (Table 2). Yield was lower in Puerto Rico due to management practices (lack of plastic mulch and staking) and fewer harvests. The larger fruit size recorded in Puerto Rico can be attributed to size being determined only at the first harvest at that location. Although statistically different, fruit set was of a similar magnitude at both locations. The somewhat poorer fruit set in Florida may have been due to slightly higher temperatures at that location.

Heritability estimates were high for all traits when estimated for a particular location (Table 2). Within-location $h^{2}$ estimates are biased upward by $\mathrm{G} \times \mathrm{E}$ variance. The effect of $\mathrm{G} \times \mathrm{E}$ variance differed depending on the trait. For fruit set, the overlocation $\mathrm{h}^{2}$ was only slightly lower than individual location estimates (Table 2). Fruit set was somewhat influenced by $\mathrm{G} x$ $\mathrm{E}$ variance, the genotype effect being about two and one-half times as large as the $G \times \mathrm{E}$ variance (Table 3 ). Heritability of yield on a combined location basis was much lower than at each location alone (Table 2). The $\mathrm{G} \times \mathrm{E}$ interaction variance for yield was highly significant and more than four times higher

Table 2. Means and heritability estimates on an $S_{1}$ family mean basis for yield per plant, fruit weight, and fruit set at Juan Diaz. Puerto Rico; Brandenton, Fla.; and combined over locations.

\begin{tabular}{llccc}
\hline \hline \multirow{2}{*}{ Trait } & Location & Mean & $\begin{array}{c}\mathrm{CV} \\
(\%)\end{array}$ & $\mathrm{h}^{2} \pm \mathrm{sE}^{\mathrm{z}}$ \\
\hline Fruit set (\%) & Puerto Rico & $45.3 \pm 0.4$ & 15.3 & $0.77 \pm 0.15$ \\
& Florida & $38.5 \pm 0.4$ & 17.1 & $0.74 \pm 0.15$ \\
& Combined & $41.9 \pm 0.3$ & 16.2 & $0.60 \pm 0.16$ \\
Yield/plant (kg) & Puerto Rico & $0.5 \pm 0.01$ & 32.5 & $0.65 \pm 0.15$ \\
& Florida & $1.5 \pm 0.02$ & 20.5 & $0.81 \pm 0.14$ \\
& Combined & $1.0 \pm 0.01$ & 24.6 & $0.14 \pm 0.19$ \\
Fruit wt (g) & Puerto Rico & $62.0 \pm 0.8$ & 21.3 & $0.89 \pm 0.14$ \\
& Florida & $51.1 \pm 0.4$ & 14.4 & $0.97 \pm 0.14$ \\
& Combined & $56.5 \pm 0.4$ & 18.9 & $0.92 \pm 0.14$ \\
\hline
\end{tabular}

${ }^{7}$ Heritabilities greater than twice their standard error are considered significant.

Table 3. Variance components and standard errors of phenotypic variance among $\mathrm{S}_{1}$ family means analyzed over locations. ${ }^{z}$

\begin{tabular}{lccc}
\hline \hline Trait & $\begin{array}{c}\text { Genetic } \\
\text { variance }\end{array}$ & $\begin{array}{c}\mathrm{G} \times \mathrm{E} \\
\text { variance }\end{array}$ & $\begin{array}{c}\text { Environmental } \\
\text { variance }\end{array}$ \\
\hline Fruit set $(\%)$ & $26.3 \pm 6.85$ & $10.2 \pm 2.63$ & 7.64 \\
Yield/plant $(\mathrm{kg})$ & $0.007 \pm 0.0092$ & $0.0325 \pm 0.0060$ & 0.0095 \\
Fruit wt $(\mathrm{g})$ & $479 \pm 4.7$ & $20.2 \pm 5.8$ & 19.01 \\
\hline
\end{tabular}

${ }^{2}$ Variances greater than twice their standard error are considered significant. 
than the nonsignificant genetic variance. Thus, the combined (over-locations) $\mathrm{h}^{2}$ estimate was not different from zero (Tables 2 and 3). Other workers (Poysa et al., 1986; Shelby et al., 1978; Stoffela et al., 1984) have found significant $\mathrm{G} \times \mathrm{E}$ interaction for yield in tomato under temperate temperatures. The genetic variance of fruit weight was more than 20 times the magnitude of the $\mathrm{G} \times \mathrm{E}$ variance, thus its combined-location $\mathrm{h}^{2}$ remained as high as the within-location estimates (Tables 2 and 3 ). These $h^{2}$ estimates indicate that response to selection in this population, within or across locations, would be expected for fruit weight and fruit set under high-temperature conditions. Because of the large $\mathrm{G} \times \mathrm{E}$ compared to genetic variance for yield, selection for that trait may not be effective under hightemperature conditions.

Heritability calculated from the variance among $\mathrm{S}_{1}$ family means can be biased by dominance effects (Hallauer and $\mathrm{Mi}^{-}$ randa, 1981). The degree of bias is a function of gene frequencies. If dominance is not the major component of genetic variance and if gene frequencies are not too high, using the genetic variance among $S_{1}$ families to estimate $h_{2}$ is not likely to cause serious bias. Previous studies have found that genetic variance of yield (Hanna and Hernandez, 1982a) and fruit set (El Ahmadi and Stevens, 1979) is largely additive. However, Shelby et al. (1978) suggested that dominance was important for fruit set. If this is true, then our estimates of heritability may be over- or under-estimated depending on gene frequencies.

We regarded the same trait measured in Florida and Puerto Rico as separate traits to determine between-locations (Puerto Rico-Florida) genetic correlations (Table 4). The high Puerto Rico-Florida genetic correlation for fruit weight suggests that most large-fruited genotypes selected at one site likely would perform well in other high-temperature sites. The intermediate Puerto Rico-Florida genetic correlation for fruit set suggests that, to some extent, different physiological mechanisms, under different genetic controls, influence this trait in different environments. Several studies have found that poor fruit set cannot be attributed to any one cause (El Ahmadi and Stevens, 1979; Hanna and Hernandez, 1982b). Nevertheless, at least some of the phenotypic covariance between locations appears to be the result of common genetic controls of fruit set in both Florida and Puerto Rico. At least some genotypes selected at one site likely would exhibit good fruit set at other sites. The non-significant genetic correlation for yield suggests that genes controlling yield in Puerto Rico were not the same as those in Florida. Selection for increased yield in one high-temperature environment may not be expected to result in similar improvements in another environment.

To determine whether $\mathrm{G} \times \mathrm{E}$ variance of a trait was caused by differences in the magnitude of the responses of genotypes or by differences in rankings of the genotypes across environments, we calculated the correlation of family ranks at Florida vs. Puerto Rico. The rank correlations between locations were somewhat lower than the genetic correlations (Table 4). The

Table 4. Genetic $\left(r_{G}\right)$, phenotypic $\left(r_{p}\right)$, and rank $\left(r_{R}\right)$ correlations $( \pm \mathrm{SE})$ between Florida and Puerto Rico for percent fruit set, yield per plant, and fruit weight. ${ }^{2}$

\begin{tabular}{lcrc}
\hline \hline Trait & $r_{\mathrm{G}}$ & \multicolumn{1}{c}{$r_{\mathrm{P}}$} & \multicolumn{1}{c}{$r_{\mathrm{R}}$} \\
\hline Fruit set & $0.59 \pm 0.09$ & $0.45 \pm 0.08$ & $0.38 \pm 0.09$ \\
Yield/plant & $0.18 \pm 0.14$ & $-0.83 \pm 0.03$ & $0.03 \pm 0.10$ \\
Fruit wt & $0.92 \pm 0.02$ & $0.86 \pm 0.03$ & $0.87 \pm 0.02$ \\
\hline \hline
\end{tabular}

${ }^{7}$ Correlations greater than twice their standard error are considered significant. intermediate $\mathrm{G} \times \mathrm{E}$ interaction of fruit set appears to be the result of both differences in rank from one location to another and magnitude of response. The nonsignificant rank correlation for yield suggests that a $\mathrm{G} \times \mathrm{E}$ interaction was due to betweenlocation differences in rank of family means. The high rank correlation for fruit weight agrees with the finding of a small $G$ $\times \mathrm{E}$ interaction. Families had similar fruit weight rankings at Puerto Rico and Florida, suggesting that the large-fruited genotypes in Puerto Rico would also generally be large-fruited in Florida.

Genetic correlations between set and yield were strongly positive, while those between set and fruit weight, and fruit weight and yield, were negative (Table 5). Previous workers have found low positive or nonsignificant genetic correlations between yield and fruit weight under moderate temperatures (Cuartero and Cubero, 1982; Giberal et al., 1982; Peirce and Currence, 1959). We found fruit set, fruit weight, and yield to be at least partially under common genetic control under the high temperatures of this study. Our results indicate that selection for improved hightemperature yield would tend to result in small fruit weight and' increased fruit set. Likewise, selection for fruit set under high temperatures would result in increased yield at high temperature, but reduced fruit weight. Yield under moderate temperatures might not be genetically correlated with high-temperature fruit set.

The high $\mathrm{h}^{2}$ estimates in this study suggest that high-temperature fruit set can be easily improved. Combining this fruitsetting ability with high fruit weight will be difficult in tomato populations that have genetic correlations similar to those found in this study. Because of the negative genetic correlation between fruit weight and set, progress toward the goal of largefruited, heat-tolerant materials may be slow. If the negative correlation between fruit weight and set is partly due to linkage, several generations of random mating before selection might improve the relationship between these two traits. Scott et al. (1986) reported that one method to improve fruit size and maintain fruit-setting ability was to make hybrids between largefruited, heat-sensitive parents and smaller-fruited, heat-tolerant parents. Use of selection indices should also help to maximize selection of two negatively correlated traits (Hallauer and Miranda, 1988). Although yield is an easier trait to measure than fruit set, indirect selection for high-temperature yield would not be an efficient way to improve fruit set because of the low

Table 5. Genetic $\left(r_{G}\right)$ and phenotypic $\left(r_{p}\right)$ correlations $( \pm \mathrm{SE})$ between percent fruit set, yield per plant, and fruit weight within and combined over locations.

\begin{tabular}{llcc}
\hline \hline Traits & Location & \multicolumn{1}{c}{$r_{\mathrm{G}}$} & \multicolumn{1}{c}{$r_{\mathrm{P}}$} \\
\hline $\begin{array}{l}\text { Fruit set vs. } \\
\text { yield/plant }\end{array}$ & Florida & $0.71 \pm 0.07$ & $0.61 \pm 0.06$ \\
& Puerto Rico & $0.74 \pm 0.07$ & $0.52 \pm 0.07$ \\
& Combined & $1.29 \pm 0.00^{\mathrm{y}}$ & $0.61 \pm 0.06$ \\
Fruit set & & & \\
$\quad$ vs. fruit wt & Florida & $-0.68 \pm 0.06$ & $-0.58 \pm 0.07$ \\
& Puerto Rico & $-0.49 \pm 0.09$ & $-0.45 \pm 0.08$ \\
& Combined & $-0.92 \pm 0.02$ & $-0.66 \pm 0.06$ \\
Yield/plant & & & \\
vs. fruit wt & Florida & $-0.25 \pm 0.11$ & $-0.21 \pm 0.10$ \\
& Puerto Rico & $-0.50 \pm 0.10$ & $-0.34 \pm 0.09$ \\
& Combined & $-0.84 \pm 0.09$ & $-0.31 \pm 0.09$ \\
\hline
\end{tabular}

${ }^{2}$ Correlations greater than twice their standard error are considered significant.

${ }^{y}$ Coefficient was > 1.0, possibly due to sampling error. 
heritability of yield. A selection index combining both these traits may be effective in improving high-temperature yield and fruit set.

\section{Literature Cited}

Cuartero, J. and J.I. Cubero. 1982. Phenotypic, genotypic and environmental correlation in tomato (Lycopersicon esculentum). Euphytica 31:151-159.

El Ahmadi, A.B. and M.A. Stevens. 1979. Reproductive responses of heat-tolerant tomatoes to high temperatures. J. Amer. Soc. Hort. Sci. 104:686-691.

Falconer, D.S. 1981. Introduction to quantitative genetics. 2nd ed. Longman, New York.

Giberal, G., A.A. Boe, W.R. Simpson, and D.O. Everson. 1982. Evaluation of F1 hybrid tomato cultivars for earliness, fruit size, and yield using diallel analysis. J. Amer. Soc. Hort. Sci. 107:243247.

Hallauer, A.R. and J.B. Miranda, Fo. 1988. Quantitative genetics in maize breeding. 2nd ed. Iowa State University Press, Ames. p. 21114.

Hanna, H.Y. and T.A. Hernandez. 1982a. Combining ability for fruit set, flower drop, and underdeveloped ovaries in some heat-tolerant tomatoes. HortScience 173760-761.

Hanna, H.Y. and T.A. Hernandez. 1982b. Response of six tomato genotypes under summer and spring weather conditions in Louisiana. HortScience 17:758-759.
Jan-orn, J., C.O. Gardner, and W.M. Ross. 1976. Quantitative genetic studies of the NP3R random mating grain sorghum population. Crop Sci. 16:489-496.

Legg, P.D., D.F. Matzinger, and T.J. Mann. 1965. Genetic variation and covariation in a Nicotiana tabacum L. synthetic two generations after synthesis. Crop Sci. 5:30-35.

Peirce, L.C. and T.M. Currence. 1959. The efficiency of selecting for earliness, yield, and fruit size in a tomato cross. Proc. Amer. Soc. Hort. Sci. 73:294-304.

Poysa, V.W., R. Garton, W.H. Courtney, J.G. Metcalf, and J. Muehmer. 1986. Genotype-environment interactions in processing tomatoes in Ontario. J. Amer. Soc. Hort. Sci. 111:293-297.

Scott, J.W., R.B. Volin, H.H. Bryan, and S.M. Olson. 1986. Use of hybrids to develop heat tolerant tomato cultivars. Proc. Fla. State Hort. Soc. 99:311-314.

Shelby, R.A., W.H. Greenleaf, and C.M. Peterson. 1978. Comparative floral fertility in heat tolerant and heat sensitive tomatoes. J. Amer. Soc. Hort Sci. 103:778-780.

Stoffella, P.J., H.H. Bryan, T.K. Howe, J.W. Scott, S.J. Locascio, and S.M. Olson. 1984. Stability differences among fresh market tomato genotypes. I. Fruit yields. J. Amer. Soc. Hort. Sci. 109:615618 .

Villareal, R.L. and A.H. Lai. 1978. Development of heat-tolerant tomato varieties in the tropics. First Intl. Sym. Trop. Tomato. Asian Veg. Res. of Development Ctr., Shanhua, Taiwan, Republic of China. p. $188-200$. 